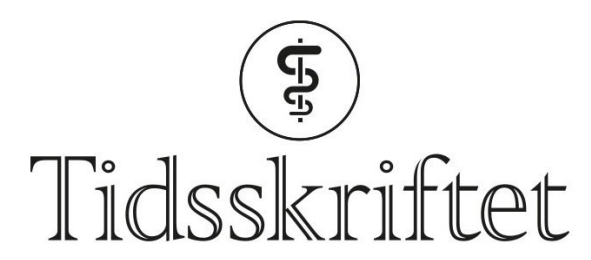

DEN NORSKE LEGEFORENING

\title{
Norge er i ferd med å stanse hivepidemien
}

KRONIKK

\section{ROBERT WHITTAKER}

E-post: robert.whittaker@fhi.no

Robert Whittaker er forsker ved Seksjon for luft-, blod- og seksuell smitte, Folkehelseinstituttet.

Forfatteren har fylt ut ICMJE-skjemaet og oppgir ingen interessekonflikter.

\section{ØIVIND NILSEN}

Øivind Nilsen er seniorrådgiver ved Seksjon for luft-, blod- og seksuell smitte, Folkehelseinstituttet. Forfatteren har fylt ut ICMJE-skjemaet og oppgir ingen interessekonflikter.

\section{ARILD JOHAN MYRBERG}

Arild Johan Myrberg er seniorrådgiver ved Divisjon folkehelse og forebygging, Helsedirektoratet. Forfatteren har fylt ut ICMJE-skjemaet og oppgir ingen interessekonflikter.

\section{ROLF M. ANGELTVEDT}

Rolf M. Angeltvedt er daglig leder i Stiftelsen Helseutvalget.

Forfatteren har fylt ut ICMJE-skjemaet og oppgir ingen interessekonflikter.

\section{BENTE MAGNY BERGERSEN}

Bente Magny Bergersen er seksjonsoverlege ved Infeksjonsmedisinsk poliklinikk, Oslo universitetssykehus, Ullevål.

Forfatteren har fylt ut ICMJE-skjemaet og oppgir ingen interessekonflikter.

\section{HILDE KLØVSTAD}

Hilde Kløvstad er seniorrådgiver ved Seksjon for luft-, blod- og seksuell smitte, Folkehelseinstituttet. Forfatteren har fylt ut ICMJE-skjemaet og oppgir ingen interessekonflikter.

Et av delmålene i FNs bærekraftsmål er å stanse hiv/aidsepidemien innen 203o. Den første milepælen, det såkalte 9o-9o-9o-målet, skal oppnås i år. Vi mener Norge har nådd målet. 


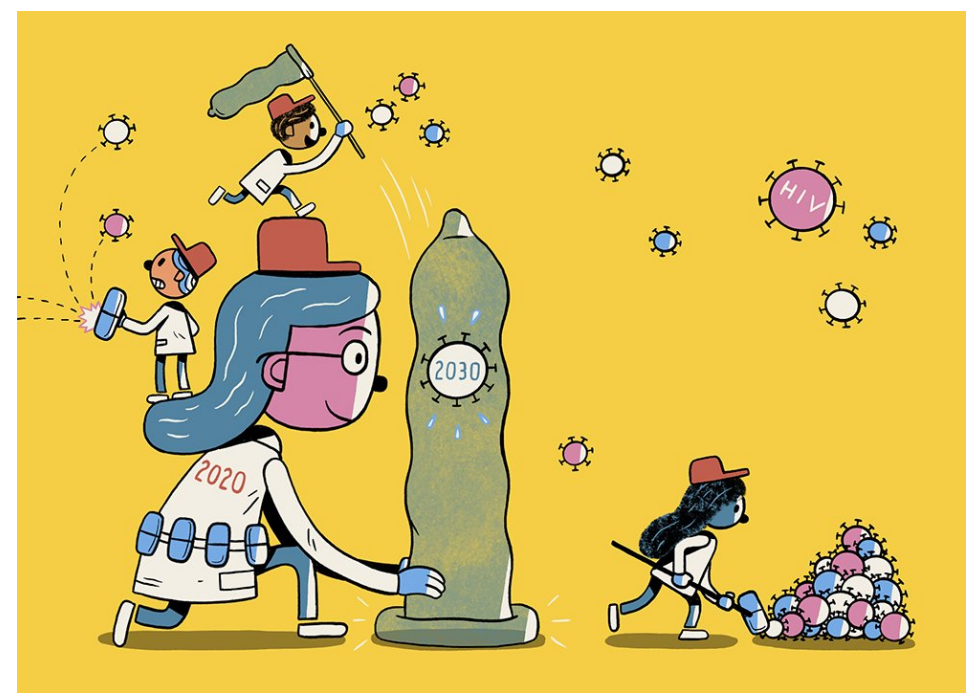

Illustrasjon: Eivind Gulliksen / desillustrert

Det er nesten 40 år siden hiv/aidsepidemien ble en ledende årsak til sykdom og tidlig død verden rundt. Hiv er fortsatt en stor global folkehelsetrussel. I 2018 ble det estimert at 38 millioner personer levde med hiv, og det var nesten 800 ooo aidsrelaterte dødsfall (1). Effektiv antiretroviral behandling har gradvis redusert sykelighet og dødelighet hos personer med hiv $(2,3)$ og har forebygget videre smitte $(4)$. Dette er bakgrunnen for det internasjonale målet om å stanse hiv/aidsepidemien innen 2030 (5). En viktig milepæl er 90-90-90-målet. Det er et uttrykk for en sammenhengende oppfølging (continuum of care), der alle land innen 2020 skal ha diagnostisert minst $90 \%$ av personer som lever med hiv, $90 \%$ av de diagnostiserte skal stå på behandling og $90 \%$ av disse skal være effektivt virussupprimert (5).

\section{0-mål nr. 1}

Det første 9o-målet handler om å finne mørketallet for personer som lever med hiv. Det er ikke mulig å beregne dette med observerte data, men tilbakeberegningsmodeller basert på nasjonale overvåkingsdata for antall hiv- og aidsdiagnoser per år kan brukes i stedet for å estimere tid fra smitte til diagnose, insidenstrenden over tid, og dermed antall udiagnostiserte tilfeller $(6,7)$.

Folkehelseinstituttet har estimert mørketallet blant personer 15 år eller eldre i Norge i slutten av 2018 med bruk av data fra Meldingssystem for smittsomme sykdommer (MSIS). Ved bruk av to ulike modelleringsmetoder er det estimert at omtrent 5 ooo personer lever med hiv i Norge og at det er et mørketall på 7-10 \% (355-520 udiagnostiserte infeksjoner). Modellen estimerte færre nye infeksjoner enn nye diagnoser per år siden 2008. Dermed er det det siste tiåret en nedadgående trend i antall udiagnostiserte hivinfeksjoner (8).

Men resultater er ikke mer pålitelige enn tallgrunnlaget man legger inn i modellen. I Norge ble hivinfeksjon meldt anonymt til MSIS frem til mars 2019. Dette har i praksis gjort det umulig å koble MSIS-data med data fra andre helseregistre for å selektere bort meldte hivtilfeller som er døde eller har utvandret. I tillegg utgjør innvandrere smittet før ankomst til Norge en betydelig andel av alle hivdiagnoser rapportert til MSIS (figur 1) (9). 


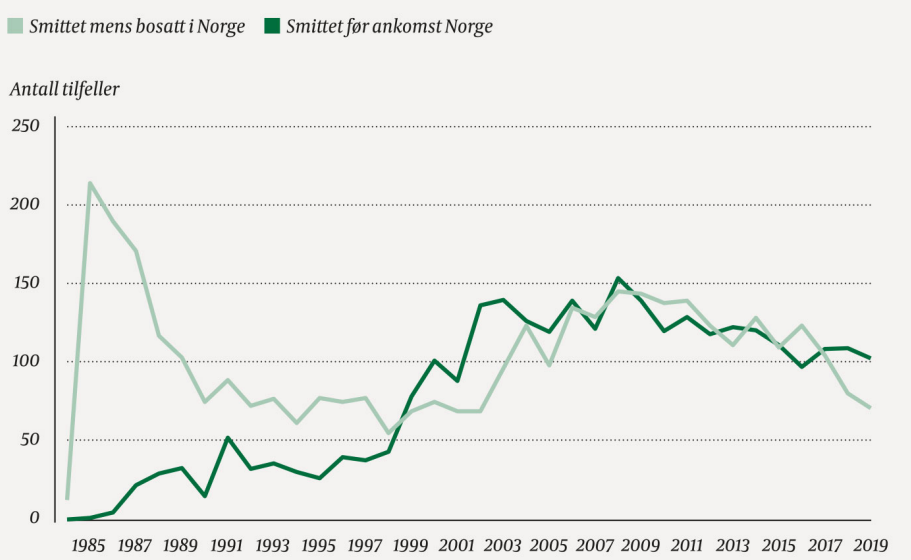

Figur 1 Antall hivinfeksjon i Norge meldt til Meldingssystem for smittsomme sykdommer(MSIS) $i$ perioden 1984-2019, etter diagnoseår og hvorvidt de med hiv var bosatt $i$ Norge ved smittetidspunktet (9).

De mest brukte tilbakeberegningsmodellene tar ikke hensyn til tidspunkt for innvandring, noe som betyr at den estimerte insidenstrenden, og dermed mørketallet, kan inkludere personer med hiv som ikke bor i Norge. Disse begrensningene vil lede til et overestimat i antall personer som lever med hiv i Norge, og dermed også antall udiagnostiserte. Overestimatet vises tydelig gjennom en sammenligning med antall hivpasienter under oppfølging ( $n=4$ og1, se neste avsnitt), ettersom det antas å være få personer som lever med diagnostisert hivinfeksjon i Norge som ikke er under oppfølging.

\section{9o-mål nr. 2 og 3}

I Norge anbefales det at alle pasienter med nyoppdaget hivinfeksjon starter antiretroviral behandling så raskt som mulig, uavhengig av CD4-tall (10). Foreløpig mangel på et nasjonalt kvalitetsregister for hivbehandling medfører at Norge ikke har et system for systematisk innsamling av nasjonale data om behandlingsstatus for personer som lever med hiv. For å fastslå antallet hivpasienter under oppfølging, antallet under behandling og antallet med virussuppresjon i Norge gjennomførte Folkehelseinstituttet ved årsskiftet 2019/20 en undersøkelse blant de infeksjonsmedisinske avdelingene som følger opp hivpasienter. 24 avdelinger oppga til sammen 4 og1 hivpasienter under oppfølging, hvorav $98 \%$ fikk hivbehandling og $96 \%$ av disse var fullt virussupprimert (< 5 o kopier/ml) ved siste kontroll (9). Dette er et svært godt resultat. Norge er ikke bare innenfor det andre og tredje 9o-målet for 2020, men også de tilsvarende 95-95-95-målene som er satt for 2030 (11).

Det er estimert at mørketallet blant de som lever med hiv i Norge er på 7-10 \%

Hvis man går ut fra at 93 \% av personer som lever med hiv er diagnostisert (8), 98 \% av disse står på behandling og 96 \% av disse er virussupprimert (9), betyr det at ca. 87 \% av personer som lever med hiv i Norge er virussupprimert. Det er en av de høyeste andelene blant de ca. 20 landene som anses å ha oppnådd målet $(12,13)$.

\section{Mot slutten av hivepidemien i Norge}

Fremgangen i hivarbeidet har vært betydelig de siste årene. Strategien krever tiltak for å øke testaktiviteten, tidlig diagnostikk, tiltak for å sikre rask henvisning til og oppfølging hos hivspesialist etter diagnose (linkage to care) samt primærforebyggende tiltak som økt kondombruk og bruk av preeksponeringsprofylakse (PrEP) blant de mest risikoutsatte.

Personer som har vært i risiko for å ha blitt hivsmittet, bør alltid tilbys hivtest. I tillegg er det opprettet egne hivtesttilbud spesielt beregnet for menn som har sex med menn. Innvandrere som kommer fra land med høy forekomst av hiv og/eller tilhører tradisjonelle risikogrupper, bør tilbys testing for hiv innen tre måneder etter ankomst (14). 
Ulike nasjonale tiltak for å øke testfrekvensen i risikoutsatte grupper er implementert blant annet gjennom $ø$ kt tilgjengelighet til lavterskeltilbud og hurtigtesting for hiv. For eksempel har tjenester som drop in-tilbudet SjekkPunkt vist seg å kunne nå menn som har sex med menn-grupperinger som ellers kan være vanskelig å nå (15). Data fra Olafiaklinikken viser $\emptyset \mathrm{kt}$ testaktivitet for seksuelt overførbare infeksjoner blant menn som har sex med menn (16), og nasjonale spørreundersøkelser i denne gruppen tyder på økt testaktivitet for hiv og generelt høy kunnskap om hvordan hiv smitter (17). Imidlertid viser den siste nasjonale spørreundersøkelsen i 2017 at det finnes potensial for å øke testaktiviteten blant disse mennene enda mer (17). Vi mangler data om testaktivitet for andre risikogrupper, som asylsøkere, innvandrere og heteroseksuelle menn som risikerer smitte på ferie i Sørøst-Asia.

Det siste tiåret er det en nedadgående trend i antall udiagnostiserte hivinfeksjoner

De gode resultatene for det andre og tredje 9o-målet gjenspeiler hivbehandlingstilbudet i Norge. Hivbehandling er gratis og innebærer tett og spesialisert oppfølging med gratis kontroller for alle som oppholder seg i landet. Dessuten har endrede nasjonale faglige retningslinjer med implementering av testing og behandling (test and treat) uavhengig av pasientens CD4-nivå bidratt til rask igangsetting av behandling $(17,18)$. Gjennom tett samarbeid kan også de ulike hurtigtesttilbudene sette personer med positivt testresultat $\mathrm{i}$ kontakt med spesialisthelsetjenesten for umiddelbar oppfølging.

Et kvalitetsregister for hivpasienter er nå godkjent og under etablering ved Oslo universitetssykehus, Ullevål. Dette vil gi mulighet for å samle inn data om behandlingsstatus for hivsmittede personer ut over arbeidet med det andre og tredje 9omålet. Et eksempel er kvalitetsregistret InfCareHIV i Sverige, der det jobbes for et fjerde 9omål med fokus på forbedret livskvalitet for personer som lever med hiv (19). Dessuten vil et nasjonalt kvalitetsregister for hivpasienter, i tillegg til nominativ rapportering til MSIS, gi mulighet for å bruke mer avanserte modelleringsmetoder og finslipe mørketallsestimatet (8).

Kondombruk er fortsatt et av de viktigste primærforebyggende tiltakene. Den siste nasjonale spørreundersøkelsen blant menn som har sex med menn, i en gruppe som er blant de mest seksuelt aktive og der flesteparten identifiserte seg som homofile, indikerer at det fremdeles pågår mye risikosex med ikke-faste partnere i denne gruppen (17).

Kondombruk er fortsatt et av de viktigste primærforebyggende tiltakene

Menn som har sex med menn er blant dem som i Norge enkelt kan benytte seg av målrettede tilbud om bestilling av gratis kondomer og glidemiddel. Bruk av preeksponeringsprofylakse vil også være et viktig virkemiddel i forebygging av hiv blant personer med høyrisikoadferd. Dette ble tilgjengelig i Norge uten kostnad for brukerne fra januar 2017 og kan effektivt redusere risikoen for å bli smittet med hiv før mulig eksponering for viruset (20). Ifølge tall fra Reseptregisteret fra juni 2020 fikk 1633 personer utskrevet PrEP-midler minst én gang i 2018 og 2019. Størst antall PrEP-brukere tilhører Olafiaklinikken og er i all hovedsak seksuelt aktive menn som har sex med menn (21). $\varnothing \mathrm{kt}$ bevissthet om smitterisiko og sykdomstegn blant risikogrupper samt åpen kommunikasjon om hivstatus og PrEP-bruk ved sex med ikke-faste partnere er også viktig for å forebygge hivsmitte.

Det er gledelig at Norge har oppnådd 90-90-9o-målet. Vi må nå ruste opp enda mer i kampen for å nå det store målet: Ingen i Norge skal smittes med hiv, og alle personer som lever med hiv i Norge, skal kunne leve et tilnærmet normalt liv.

1. The Joint United Nations Programme on HIV/AIDS. UNAIDS Data 2019.

https://www.un.org/youthenvoy/2013/o8/unaids-joint-united-nations-programme-on-hivaids/ Lest 26.10.2020. 
2. Wandeler G, Johnson LF, Egger M. Trends in life expectancy of HIV-positive adults on antiretroviral therapy across the globe: comparisons with general population. Curr Opin HIV AIDS 2016; 11: 492-500. [PubMed][CrossRef]

3. Lifson AR, Grund B, Gardner EM et al. Improved quality of life with immediate versus deferred initiation of antiretroviral therapy in early asymptomatic HIV infection. AIDS 2017; 31: 953-63. [PubMed][CrossRef]

4. Rodger AJ, Cambiano V, Bruun T et al. Risk of HIV transmission through condomless sex in serodifferent gay couples with the HIV-positive partner taking suppressive antiretroviral therapy (PARTNER): final results of a multicentre, prospective, observational study. Lancet 2019;393:2428-38. [PubMed][CrossRef]

5. Joint United Nations Programme on HIV/AIDS. 90-90-90: An ambitious treatment target to help end the AIDS epidemic. https://www.unaids.org/en/resources/909o9o Lest 26.10.2020.

6. Stover J, Glaubius R, Mofenson L et al. Updates to the Spectrum/AIM model for estimating key HIV indicators at national and subnational levels. AIDS 2019;33 (suppl 3): S227-34. [PubMed][CrossRef]

7. ECDC HIV Modelling Tool User Manual. Version 1.3.o. Solna: European Centre for Disease Prevention and Control, 2017.

https://www.ecdc.europa.eu/sites/default/files/documents/HIV-modelling-tool-v1.3.o-manual.pdf Lest 26.10.2020.

8. Whittaker R, Case KK, Nilsen $\emptyset$ et al. Monitoring progress towards the first UNAIDS 9o-9o-9o target in key populations living with HIV in Norway. BMC Infect Dis 2020; 20: 451. [PubMed][CrossRef]

9. Årsrapport 2019: Overvåkning av seksuelt overførbare infeksjoner 2020. Oslo: Folkehelseinstituttet; 2020. https://www.fhi.no/publ/2020/arsrapport-2019-seksuelt-overforbare-infeksjoner/ Lest 26.10.2020.

10. Faglige retningslinjer for oppfølging og behandling av hiv. Oslo: Den Norske Legeforeningen, 2020. https://www.legeforeningen.no/contentassets/a15833e35cff41b2b63ad46615b106od/hivretningslinjer2o 20_final120520.pdf Lest 26.10.2020.

11. Understanding Fast-Track: accelerating action to end the AIDS epidemic by 2030. Geneva: Joint United Nations Programme on HIV/AIDS, 2015.

12. Gisslén M, Svedhem V, Lindborg L et al. Sweden, the first country to achieve the Joint United Nations Programme on HIV/AIDS (UNAIDS)/World Health Organization (WHO) 90-90-9o continuum of HIV care targets. HIV Med 2017; 18:305-7. [PubMed][CrossRef]

13. Marsh K, Eaton JW, Mahy M et al. Global, regional and country-level 9o-9o-9o estimates for 2018: assessing progress towards the 2020 target. AIDS 2019; 33 (suppl 3): S213-26. [PubMed][CrossRef]

14. Folkehelseinstituttet. Hivinfeksjon/Aids - veileder for helsepersonell.

https://www.fhi.no/nettpub/smittevernveilederen/sykdommer-a-a/hivinfeksjonaids-veileder-for-hel/ Lest 26.10.2020.

15. Moseng BU, Bjørnshagen V. Are there any differences between different testing sites? A crosssectional study of a Norwegian low-threshold HIV testing service for men who have sex with men. BMJ Open 2017; 7: e017598. [PubMed][CrossRef]

16. Olafiaklinikken. Flere menn som har sex med menn tester seg oftere for kjønnssykdommer. https://oslo-universitetssykehus.no/avdelinger/klinikk-for-kirurgi-inflammasjonsmedisin-og-transpla ntasjon/avdeling-for-revmatologi-hud-og-

infeksjonssykdommer/olafiaklinikken/nyheter/olafiaklinikken-blogger\#flere-menn-som-har-sexmed-menn-tester-seg-oftere-for-kjonnssykdommer Lest 26.10.2020.

17. Europeisk menn som har sex med menn internettundersøkelse: Norske resultater. Oslo: Folkehelseinstituttet, 2020 .

https://www.fhi.no/globalassets/dokumenterfiler/rapporter/2020/europeisk-menn-som-har-sex-medmenn-internettundersokelse-2017-rapport-2020.pdf Lest 26.10.2020.

18. Årsrapport for 2016 med plan for forbedringstiltak. Oslo: Norsk kvalitetsregister for hiv, 2018.

19. Årsrapport. InfCareHIV 2018.

https://qrcstockholm.se/wp-content/uploads/2019/o9/\%C3\%85rsrapport-InfCareHIV-2018.pdf Lest 26.10.2020. 
20. Anderson PL, Glidden DV, Liu A et al. Emtricitabine-tenofovir concentrations and pre-exposure prophylaxis efficacy in men who have sex with men. Sci Transl Med 2012; 4:151ra125.

[PubMed][CrossRef]

21. Hanlon M, MacLeod J, Pettersen FO et al. Evalueringsrapport: Oppdatering av PrEPimplementeringen i Norge. Oslo: Nasjonal kompetansetjeneste for seksuelt overførbare infeksjoner og Olafiaklinikken, 2019.

https://oslo-universitetssykehus.no/seksjon/nasjonal-kompetansetjeneste-for-seksuelt-overforte-infek sjoner/Documents/PrEP\%2oimplementeringen\%20i\%2oNorge.pdf Lest 26.10.2020.

Publisert:30. november 2020. Tidsskr Nor Legeforen. DOI: 10.4045/tidsskr.20.0748

Mottatt 18.9.2020, første revisjon innsendt 20.10.2020, godkjent 26.10.2020.

(C) Tidsskrift for Den norske legeforening 2020. Lastet ned fra tidsskriftet.no 